\title{
A low-cost endoscopy trainer for novice endoscopy training in COVID-19
}

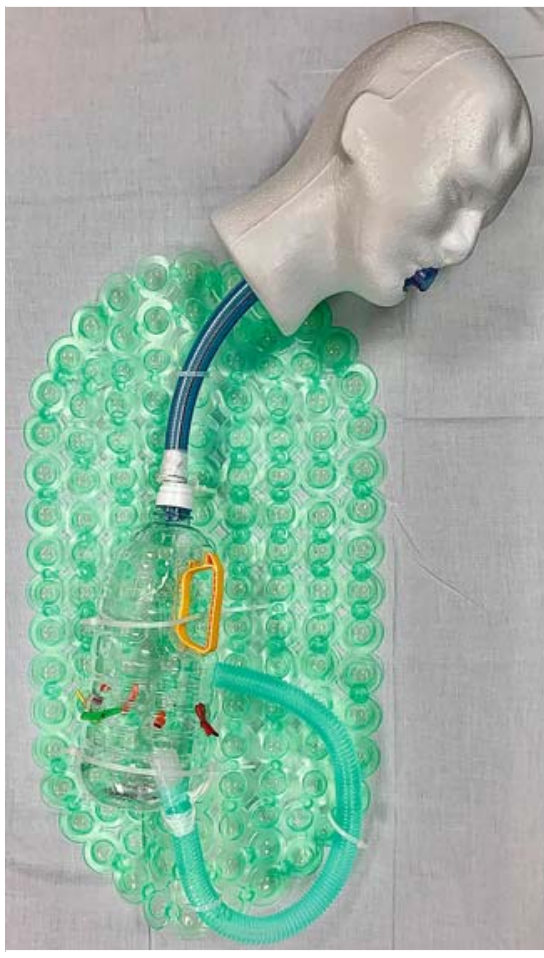

- Fig. 1 Components of a low-cost model for endoscopy training.

The coronavirus disease 2019 (COVID19) pandemic has significantly impacted gastroenterology and endoscopy training. Nonurgent endoscopies have been postponed; trainees have been redeployed; and trainee participation in endoscopies that are still being executed has also been limited [1].

For most gastroenterologists, endoscopy training begins with gastroscopy. More than 200 gastroscopies may be required before trainees can be certified as proficient [2]. Endoscopy trainees from all around the world have reported a reduction in case volume, leading to trainee concerns regarding their ability to develop sufficient procedural competency in a training period often of finite duration [3].

Although nothing can replace active participation in procedures, hands-on models have long been used as effective aids
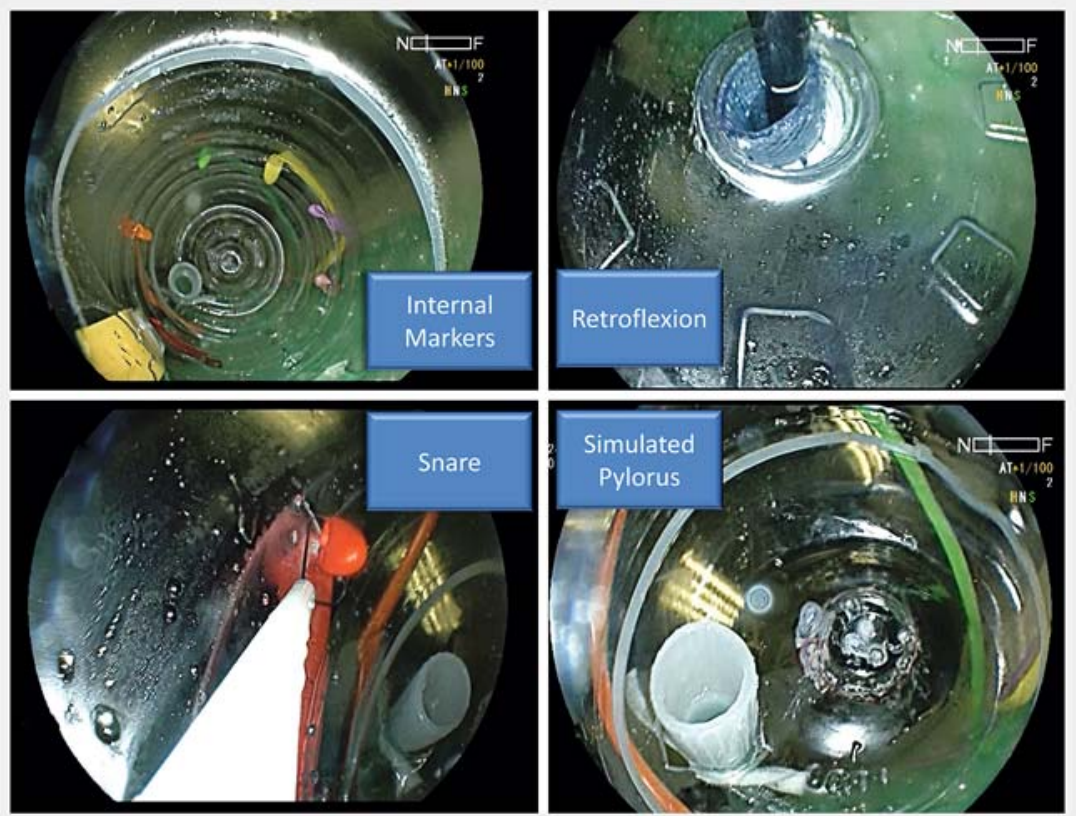

- Fig. 2 Internal view of the model.
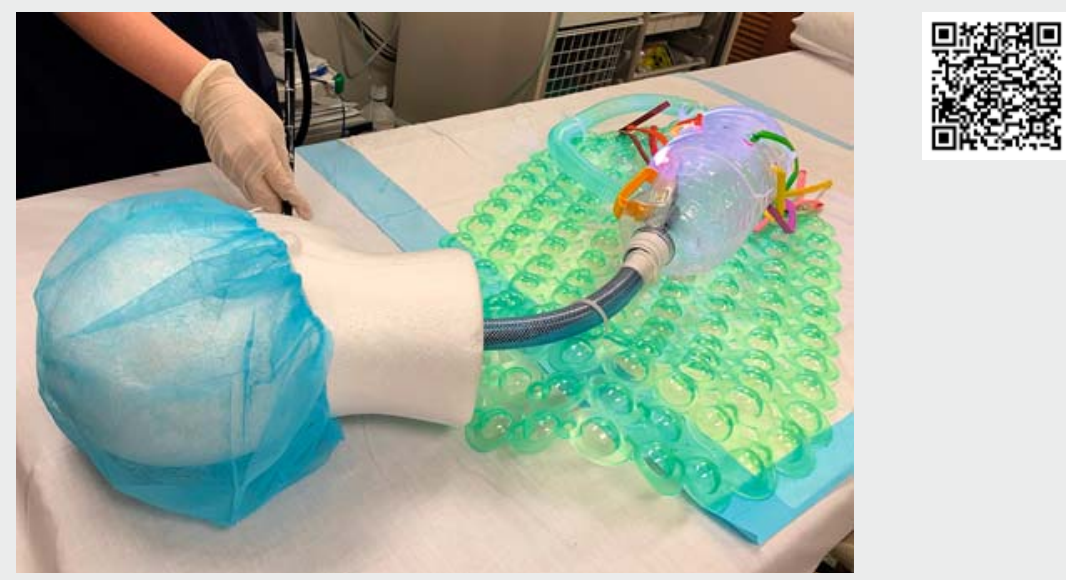

Video 1 A low-cost endoscopy training model for novice endoscopy training.

for endoscopic education. This can help trainees develop the manual dexterity and familiarize themselves with the basic technical skills required prior to moving on to actual patients.
We developed a low-cost model ( $\triangleright$ Fig. 1 , - Video 1) comprising common household and hospital items including a 20-mm-diameter water hose, a 2-L plastic bottle, differently-colored balloons, 
and ventilator tubing with a total cost < $\$ 30$. This model will assist novice endoscopy trainees with learning basic endoscopic movements including scope insertion and manipulation, different methods of applying scope torque, one-handed wheel deflection, scope retroflexion, instrument targeting, and snaring of targets. The clear plastic bottle (which can be easily covered) also allows the trainee to directly visualize how their scope control movements translate to scope tip behavior, and helps to shorten the cognitive gap and to build muscle memory. This model is highly adaptable and can also be used for training and simulation of infrequent but serious events such as Sengstaken-Blakemore tube insertion. The targets can also be swapped out depending on need, with the colored balloon tip simulating a polyp ( $\mathbf{F i g . 2}$ ).

Endoscopy_UCTN_Code_TTT_1AU_2AB

\section{Competing interests}

The authors declare that they have no conflict of interest.
The authors

Chieh Sian Koo ${ }^{1}$, Kewin Tien Ho Siah ${ }^{1,2}$, How Cheng Low ${ }^{1,2}$, Calvin Jianyi Koh ${ }^{1,2}$

1 Division of Gastroenterology and Hepatology, National University Hospital, Singapore

2 Yong Loo Lin School of Medicine, National University of Singapore

Corresponding author

Calvin J. Koh, MBBS, MMed, MRCP, FAMS Endoscopy Centre, Division of Gastroenterology and Hepatology, National University Hospital, Singapore, 1E Kent Ridge Road, Singapore 119228

Fax: +65-6775-1518

calvin_j_koh@nuhs.edu.sg

\section{References}

[1] Forbes N, Smith ZL, Spitzer RL et al. Changes in gastroenterology and endoscopy practices in response to the COVID-19 pandemic: results from a North American survey. Gastroenterology 2020 . doi:10/1053/j.gastro.2020.04.071

[2] Siau K, Anderson JT, Valori R et al. Certification of UK gastrointestinal endoscopists and variations between trainee specialties: results from the JETS e-portfolio. Endosc Int Open 2019; 7: E551-E560

[3] Pawlak KM, Kral J, Khan R et al. Impact of COVID-19 on endoscopy trainees: an international survey. Gastrointest Endosc 2020. doi:10.1016/j.gie.2020.06.010
Bibliography

Endoscopy 2020; 52: E463-E464

DOI 10.1055/a-1230-3325

ISSN 0013-726X

published online 3.9 .2020

(c) 2020. Thieme. All rights reserved.

Georg Thieme Verlag KG, Rüdigerstraße 14,

70469 Stuttgart, Germany

\section{ENDOSCOPY E-VIDEOS}

https:/|eref.thieme.de/e-videos

口回 Endoscopy E-Videos is a free access online section, reporting 回궁. on interesting cases and new

techniques in gastroenterological endoscopy. All papers include a high quality video and all contributions are freely accessible online.

This section has its own submission website at https://mc.manuscriptcentral.com/e-videos 